\title{
ALLELOPATHIC EFFECT OF CASTANOPSIS KAWAKAMII FOREST LITTER ON SEED GERMINATION OF SMALL PHILIPPINE ACACIA (ACACIA CONFUSA)
}

\author{
JIN, M. R. ${ }^{1,2,3 \#}-$ WANG, Z. ${ }^{1,2,3 \#}-$ HE, Z. S. $.^{1,2,3 *}-$ JIANG, L. ${ }^{1,2,3}-$ LIU, J. F. ${ }^{1,2,3^{*}}-$ LAN, Y. Q. ${ }^{1,2,3}-$ \\ SHI, Y. W. ${ }^{4}-$ SHEN, C. X. ${ }^{4}$ \\ ${ }^{1}$ College of Forestry, Fujian Agriculture and Forestry University, Fuzhou 350002, China \\ ${ }^{2}$ Cross-Strait Nature Reserve Research Center, Fujian Agriculture and Forestry University, \\ Fuzhou 350002, China
}

${ }^{3}$ Key Laboratory of Fujian Universities for Ecology and Resource Statistics, Fuzhou 350002, China

${ }^{4}$ Administration Station of Castanopsis kawakamii Nature Reserve in Xinkou of Sanming, Sanming 365000, China

${ }^{*}$ These authors contributed equally to this work

*Corresponding authors

e-mails:fjlif@126.com; jxhzs85@fafu.edu.cn

(Received $28^{\text {th }}$ Jun 2019; accepted $16^{\text {th }}$ Oct 2019)

\begin{abstract}
Nutrient limitation constrains the regeneration of Castanopsis kawakamii seedlings in subtropical forests. Small Philippine acacia (Acacia confusa), a common tree species in mixed forests, is known for its nitrogen fixation capabilities. Therefore, we attempted to intercrop $A$. confusa in a $C$. kawakamii natural forest. However, this forest contained abundant litter, harboring ample tannins and total phenols. Whether the allelopathy of litter could constrain the seed germination of A. confusa seed was unknown. Therefore, we aimed to explore the influence of forest litter extracts on the seed germination and radicle growth of $A$. confusa. The results indicate that low concentration litter extracts promote whereas high concentrations inhibit $A$. confusa seeds. The stock solution produced the strongest inhibition, whereas the 1:160 litter extract concentration had promoted the germination rate and radicle growth. The A. confusa radicle increase was remarkable in the first eight days, and tended to decrease from day 9 to 15 . Overall, the allelopathic effect of litter is not a factor limiting the mixing of $C$. kawakamii and A. confusa. This could provide an alternative method to improving soil nutrition, thus promoting the regeneration of $C$. kawakamii seedlings.
\end{abstract}

Keywords: germination rate, germination potential, germination index, radicle length, mixed forest

\section{Introduction}

Castanopsis kawakamii is a unique subtropical evergreen broad-leaved species. It has survived as an endangered tertiary relict plant, only found in Fujian, Taiwan, Jiangxi, Guangdong, and Guangxi provinces in China (Buanjan et al., 2018). Currently, natural C. kawakamii forests are characterized by limited seed germination and seedling growth due to the low total nitrogen and total phosphorus in the soil (Su et al., 2012). As crucial aspects of a forest ecosystem, the physical and chemical properties and nutrients in the soil are significant to seedling development (Hou et al., 2011). However, previous studies mainly focused on community ecology (He et al., 2019); forest gap regeneration (He et al., 2018); natural forest, its plantation litter, and soil biochemistry cycle (Ma et al., 2015); soil microbes, biochemical characteristics (Ma et al., 2014); and soil-litter 
stoichiometry to protect this rare species (Feng et al., 2017). Little research has focused on improving soil nutrition to promote species regeneration in this forest. Thus, in this study, we aimed to replenish soil nutrients to accelerate the regeneration of $C$. kawakamii seedlings.

Consistent with the importance of rhizobia-mediated $\mathrm{N}$ partitioning, inclusion of legumes is instrumental for generating positive diversity-productivity relationships (Wang et al., 2019a). With the existence of legumes and rich nitrogen in the litter layers, Acacia confusa has powerful fixation ability. Previous reports showed that one hectare of A. confusa forest can provide $3500 \mathrm{~kg}$ of litter per year, which is equivalent to $500 \mathrm{~kg}$ of carbamide after litter decomposition (Hu et al., 2015; Tung et al., 2015; Liu, 2011). As a common tree species in mixed forests, A. confusa is cultivated in tropical and subtropical regions in southwestern and southeastern provinces in China. It has a fast growth rate, wide adaptability, high biomass, and good water retention. Mixed with Castanopsis plants, such as $C$. hainanensis, $C$. carlesii, and $C$. hystrix, A. confusa could help Castanopsis plants to grow better. A. confusa also does not cause damage to Castanopsis plants (Liu, 2011), providing an alternative method for managing $A$. confusa in natural $C$. kawakamii forest to replenish and enrich the nutrient contents and to improve the establishment and regeneration of the target seedlings.

The amount of litter and the contents of tannin and total phenol in the C. kawakamii natural forest are relatively high (Feng et al., 2017; Yang et al., 2003). The seed germination and radicle growth of $C$. kawakamii are significantly inhibited under the action of a stock solution of litter (Wang et al., 2019b). The allelochemicals produced by the litter may also affect the germination of $A$. confusa seeds. Therefore, we hypothesized that: (1) different concentrations of litter extracts have different effects on A. confusa seeds, and high concentration of litter extracts inhibit the seed germination and radicle growth; (2) under the treatment of litter, A. confusa radicles grow considerably in the early period and growth decreases later; and (3) if the litter extract promotes the germination of $A$. confusa seeds, soil $\mathrm{N}$ content may be increased to improve the regeneration of $C$. kawakamii's seedlings; if the litter extract inhibits germination, it indicates that $A$. confusa may not suitable as a mixed tree species in $C$. kawakamii natural forest. Finding other methods to improve the soil $\mathrm{N}$ content in this forest is necessary. Therefore, in this study, the extracts of $C$. kawakamii natural forest litter were used as allelopathic substances to explore the allelopathic effects of litter extracts on the germination of $A$. confusa seeds. The objective of our study was to provide a scientific basis for intercropping $A$. confusa species to improve soil nutrition, thereby accelerating the regeneration of $C$. kawakamii seedlings in this forest.

\section{Materials and methods}

\section{Study sites and natural history}

The C. kawakamii Nature Reserve is located in Sanming, Fujian Province, China, at $26^{\circ} 07^{\prime}-26^{\circ} 12^{\prime} \mathrm{N}$ and $117^{\circ} 24^{\prime}-117^{\circ} 29^{\prime}$ E. The elevation varies between 180 and $604 \mathrm{~m}$. The climate is medium subtropical monsoon, with an annual average temperature of $19.5^{\circ} \mathrm{C}$, annual precipitation around $1500 \mathrm{~mm}$, and annual relative humidity of $79 \%$. The soil type in this forest is mainly ferric acrisols with abundant humus. The research area has 700 ha of $C$. kawakamii, in which the average age of the population is about 130 years. The arbor layer is dominated by C. kawakamii, Pinus massoniana, and Schima superba. Accordingly, the population density, average tree height, diameter at 
breast height, and canopy density are estimated to be 100 individuals $/ \mathrm{hm}^{2}, 21.5 \mathrm{~m}$, $32.4 \mathrm{~cm}$, and 0.8 , respectively. The shrub layer is mainly composed of Litsea subcoriacea, Vaccinium carlesii, and Syzygium buxifolium; and the herbaceous layers are represented by Dicranopteris pedata, Gahnia tristis, and Alpinia oblongifolia (Liu et al., 2011; Ma et al., 2015).

\section{Experiment design}

The litter baskets were arranged in the east, south, west, north, and middle of the fixed plots in the C. kawakamii natural forest, and were collected monthly from Sept. 2016 to Sept. 2017. We set up a total of 10 plots and the size of each plot was designed to be about $100 \mathrm{~m}^{2}$ and the litter baskets were $1.0 \times 1.0 \mathrm{~m}$. The litter basket arrangement is shown in Figure 1. The collected litter was divided into four types: leaves, nutshells, branches, and bark. Then, we mixed the litter of each of the four types in accordance with their proportion. In the next step, we weighed $1 \mathrm{~kg}$ of each type. We collected $5 \mathrm{~kg}$ of $A$. confusa seeds from the same family for experimental materials.

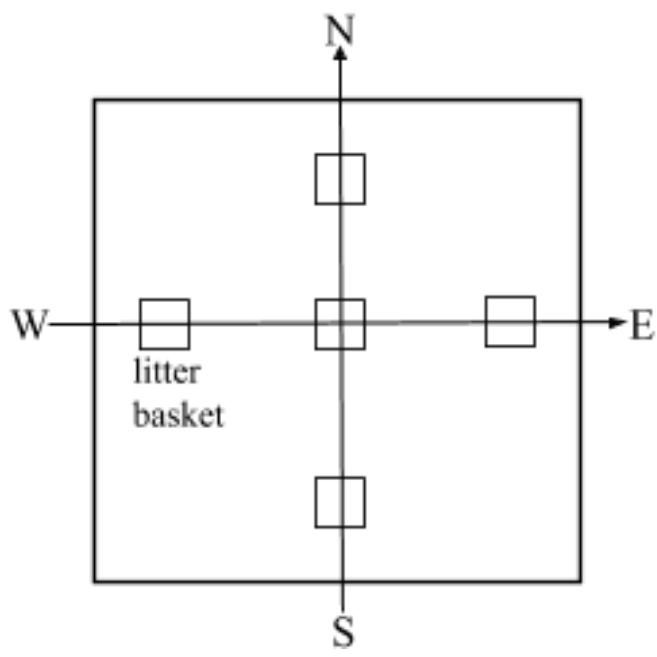

Figure 1. The location of litter baskets in each plot. The small square box represents the location of the litter basket

\section{Preparation of litter extracts}

Each kilogram of collected litter sample was washed three times with distilled water to remove surface-attached soil and humus. Next, the samples were crushed and sieved after drying in an oven. After sieving, $10 \mathrm{~g}$ of litter were placed into a $50 \mathrm{~mL}$ centrifuge tube and $15 \mathrm{~mL}$ of $70 \%$ ethanol was added. The mixture was leached twice at $80{ }^{\circ} \mathrm{C}$ for $1 \mathrm{~h}$ in a water bath. After free cooling, the samples were placed into a centrifuge at $4{ }^{\circ} \mathrm{C}$ for $5 \mathrm{~min}$ at a rotation speed at $8000 \mathrm{rpm}$. To obtain a stock solution (with three replicates), we filtered the extracts twice and then diluted the extracts to $50 \mathrm{~mL}$ with distilled water. As the extraction of litter in nature is repetitive and diverse, the range of extract types and contents is relatively wide. Ethanol was applied as an effective extraction agent to ensure polarized allelochemicals could be maximally extracted out of the litter.

The stock solution was then placed on a rotary evaporator to evaporate the ethanol. The average litter quality and annual precipitation of the $C$. kawakamii natural forest 
fixed plot from 2010 to 2017 were $11,010 \mathrm{~kg} / \mathrm{hm}^{2}$ and $1500 \mathrm{~mm} /$ year. Referring to the litter conversion (Yuan et al., 2010), 1:160 is the natural leaching concentration of the litter of natural C. kawakamii forest. Considering the rain leaching process, repeated extraction, and microbial decomposition, five concentrations were set as treatments: 1:20, 1:40, 1:80, 1:160, and 1:320. Therefore, the stock solution was diluted again with distilled water with five different concentrations. The dilution rates are listed as follows: 1:20 litter extracts (stock solution was diluted 4 times with distilled water), 1:40 litter extracts (stock solution was diluted 8 times with distilled water), 1:80 litter extracts (stock solution was diluted 16 times with distilled water), 1:160 litter extracts (stock solution was diluted 32 times with distilled water), and 1:320 litter extracts (stock solution was diluted 64 times with distilled water), and then we stored the extracts in a $4{ }^{\circ} \mathrm{C}$ refrigerator until use. During the extraction, the ethanol evaporation was incomplete. As a consequence, we also created a blank control group as a contrast that was exempted from the treatment: the same procedure was repeated but without the litter.

\section{Seed germination experiment}

The selected and same-sized $A$. confusa seeds were disinfected with $0.5 \%$ potassium permanganate for $30 \mathrm{~min}$, then washed with distilled water 3 times before arranging them evenly in a petri dish with $C$. kawakamii forest soil. The $C$. kawakamii forest soil was sterilized in a high temperature sterilization pot at $120{ }^{\circ} \mathrm{C}$ for $20 \mathrm{~min}$. The different concentrations of litter extracts were added into each petri dish, with 100 seeds placed uniformly in each petri dish. We set up a total of 6 treatments including stock solution, 1:20 litter extract, 1:40 litter extract, 1:80 litter extract, 1:160 litter extract, and 1:320 litter extract with 3 replications each with distilled water, and a blank control group as the control. The experiment conditions were cultured with a $12 \mathrm{~h}$ photoperiod at $25^{\circ} \mathrm{C}$, $12 \mathrm{~h}$ dark cycle at $15^{\circ} \mathrm{C}$, light intensity $50 \mathrm{nmol} / \mathrm{cm}^{2} / \mathrm{s}$, and relative humidity $75-80 \%$ in the incubators. We added $5 \mathrm{~mL}$ litter extract daily into the filter paper of the petri dish to maintain moisture.

We recorded the seed germination 3 days after the experiment. A $2 \mathrm{~mm}$ seed radicle was defined as seed germination, and the number of germinated seeds was recorded every day (Aldo et al., 2018). We finished the experiment when no further seed germination occurred for 3 continuous days. The radicle length measurements were recorded when the seed germination reached the peak (Wang et al., 2019b). We measured the radicle length of 20 seeds with a similar radicle length in different petri dishes after recording the seed germination for three days when the seed germination reached the peak. The length of the radicle was also measured daily with an electronic digital caliper with a resolution of $0.01 \mathrm{~mm}$. The radicle daily growth amount was simultaneously calculated by the difference in the value of the radicle length between the current day and the previous day. On the 15th day, we finished the radicle experiment when the radicle growth was generally stable. Finally, the germination rate, germination potential, germination index, allelopathic effect index, and the radicle length of seeds were thereby calculated (Bruce et al., 1988). The formulas are listed below (He et al., 2012; Gabriel et al., 2017).

$$
\text { Germination rate }=\frac{\text { number of seeds germinated }}{\text { total number of seed } s} \times 100 \%
$$




$$
\begin{gathered}
\text { Germination potential }=\frac{\text { number of seeds that were normally germinated to the highest }}{\text { total number of seeds }} \times 100 \% \\
\text { Germination index }=\Sigma \frac{G t}{D_{t}}
\end{gathered}
$$

where $D t$ refers to the number of germination days, and $G t$ refers to the number of germinated seeds in that $D t$ day.

Allelopathy index:

$$
\begin{array}{ll}
\mathrm{I}=1-\frac{C}{T} & (\text { when } T \geq C \text { ) } \\
\mathrm{I}=\frac{T}{C}-1 & (\text { when } T<C \text { ) }
\end{array}
$$

where $C$ refers to the control value, $T$ refers to the treatment value, while $I<0$ represents the inhibition effect, $I>0$ represents the promotion effect, and $I=0$ represents the neutral effect.

\section{Data analysis}

The experimental data were calculated and plotted using Excel 2016 (Microsoft, Redmond, Washington, USA). The statistical ANOVA was analyzed using SPSS 21.0 (IBM, Almonk, New York, USA). We first calculated the effect of different concentrations of litter extracts on the germination indices, radicle length, radicle growth, and allelopathy index of $A$. confusa seeds. Then, the variance analysis of these data was performed, and Tukey's test was applied in multiple comparisons to determine the significant difference among various treatments. The data were considered to be significantly different at $P<0.05$.

\section{Results}

\section{Effects of different extract concentrations on germination of A. confusa seeds}

The effects of various concentrations of litter extracts on seed germination of $A$. confusa is shown in Tables 1 and 2. A. confusa seeds demonstrated different sensitivities to different concentrations of litter extract, which generally promoted seed germination at low concentrations and inhibited it at high concentrations. We found a negative correlation between litter extract concentration and germination potential, germination rate, and germination index. The germination rate was highest with a litter concentration of 1:160, which promoted the seed germination rate. The seed germination rate was significantly lower than those of the other treatments at a concentration of 1:20, demonstrating the most inhibition of the seed germination rate. The seed germination rates under high concentration treatments (including stock solution, 1:20, and 1:40) were significantly lower than under low concentration treatments (1:160 and 1:320). High concentrations of litter extract inhibited the seed germination rate, whereas low concentrations had a promotion effect. The germination potentials for high concentration (including stock solution and 1:20) flitter extract treatments were significantly lower than for low concentration (1:80 and 1:160) treatments. The germination potential and index were the lowest for the stock solution, which revealed negative effects on the seed germination potential and index. The 
germination indexes for the high concentration (including stock solution and 1:20) treatments were significantly lower than for the low concentration litter extract treatments (including 1:80, 1:160, and 1:320). No significant differences in germination rate, potential, or index were found between distilled water and the control group. We found that when the concentration of litter extracts exceeded the dilution ratio of 1:40, the seed germination was restrained. The 1:80 dilution rate was considered the turning point for seed germination; the optimum dilution for seed germination was found to be 1:160. The 1:160 litter extract was the most appropriate concentration for the germination of A. confusa seeds.

Table 1. Effects of different concentrations of litter extracts on seed germination of A. confusa

\begin{tabular}{c|c|c|c|c|c|c}
\hline $\begin{array}{c}\text { Leaching } \\
\text { solution }\end{array}$ & $\begin{array}{c}\text { Germination } \\
\text { rate/\% }\end{array}$ & $\begin{array}{c}\text { Allelopathy } \\
\text { index }\end{array}$ & $\begin{array}{c}\text { Germination } \\
\text { potential/\% }\end{array}$ & $\begin{array}{c}\text { Allelopathy } \\
\text { index }\end{array}$ & $\begin{array}{c}\text { Germination } \\
\text { index }\end{array}$ & $\begin{array}{c}\text { Allelopathy } \\
\text { index }\end{array}$ \\
\hline Distilled water & $63.00 \pm 1 \mathrm{bcd}$ & 0.00 & $50.00 \pm 3 \mathrm{a}$ & 0.00 & $81.32 \pm 2 \mathrm{bc}$ & 0.00 \\
Control group & $61.60 \pm 1.44 \mathrm{bcd}$ & 0.03 & $47.50 \pm 3 \mathrm{abc}$ & -0.05 & $79.16 \pm 2.07 \mathrm{~cd}$ & -0.05 \\
Stock solution & $60.00 \pm 1 \mathrm{~cd}$ & -0.05 & $13.50 \pm 4.5 \mathrm{~d}$ & -0.73 & $56.06 \pm 2.36 \mathrm{f}$ & -0.33 \\
$1: 20$ & $57.00 \pm 0 \mathrm{e}$ & -0.10 & $46.00 \pm 0 \mathrm{c}$ & -0.08 & $73.77 \pm 0 \mathrm{e}$ & -0.12 \\
$1: 40$ & $60.50 \pm 1.5 \mathrm{~cd}$ & -0.07 & $46.50 \pm 2.5 \mathrm{bc}$ & -0.07 & $75.98 \pm 1.5 \mathrm{~cd}$ & -0.09 \\
$1: 80$ & $63.50 \pm 0.5 \mathrm{abc}$ & 0.05 & $52.50 \pm 0.5 \mathrm{ab}$ & 0.05 & $84.26 \pm 0 \mathrm{abc}$ & 0.01 \\
$1: 160$ & $66.00 \pm 2 \mathrm{a}$ & 0.09 & $54.50 \pm 3 \mathrm{a}$ & 0.09 & $88.61 \pm 1.28 \mathrm{a}$ & 0.06 \\
$1: 320$ & $64.00 \pm 1 \mathrm{ab}$ & 0.02 & $51.00 \pm 0 \mathrm{abc}$ & 0.02 & $81.46 \pm 1.76 \mathrm{bc}$ & -0.02 \\
\hline
\end{tabular}

The purpose of the control group is to test whether the ethanol solution added to the litter extracts affect the seed germination of $A$. confusa. Data (mean $\pm \mathrm{SD}$ ) marked with different letters in plots were significantly different under $\mathrm{p}$ level as 0.05 in the same column. The same below

Table 2. Effects of treatments on seed germination of A. confusa were tested using one-way ANOVA

\begin{tabular}{c|c|c|c|c}
\hline & df & F & P \\
\hline \multirow{2}{*}{ Germination rate } & Between groups & 7 & & \\
& Within groups & 16 & 15.815 & $<0.001^{* * * *}$ \\
& Total & 23 & & \\
\hline \multirow{2}{*}{ Germination potential } & Between groups & 7 & & $<0.001^{* * *}$ \\
& Within groups & 16 & 98.107 & \\
\hline \multirow{2}{*}{ Germination index } & Total & 23 & & $<0.001^{* * *}$ \\
& Between groups & 7 & & 122.883 \\
\hline
\end{tabular}

\section{Effects of different concentrations of extracts on radicles of A. confusa seeds}

\section{Difference in radicle length between different concentrations of extracts}

Figure 2 and Table 3 show the effects of various concentrations of litter extract on the radicle length of $A$. confusa seeds. Similar to seed germination, the different concentrations of litter extracts tended to promote radicle growth at low concentration and inhibit radicle growth at high concentration. The inhibition effect was aggravated with increasing concentration, among which the most notable effect was observed with the 
stock solution. The 1:40 to 1:160 litter extracts demonstrated a promotion effect, that was the strongest at 1:160, whereas the facilitation effect gradually weakened when the concentration was 1:320. The growth in radicle length in the early stage was not obvious for the different concentrations of litter extracts. The difference in radicle length between various concentration of litter extracts and distilled water increased with time. Significant differences in radicle length were detected among the stock solution, distilled water, and 1:160 concentration litter extract. At the end of the experiment, the average radicle lengths for 1:160 litter extract, distilled water, and stock solution were 36.09, 30.06, and $19.59 \mathrm{~mm}$, respectively. No significant differences in radicle length were found between the distilled water and control groups.



Figure 2. Effects of different concentrations of litter extracts over time on the radicle length of A. confusa seeds. The different letters (from a to d) represent the difference in radicle length among the different concentrations of the same day. Data (mean $\pm S D$ ) marked with different letters in plots were significantly different under p level as 0.05 in the same column. Compared with the control group, the treatment group were larger than the control group indicates that the radicle growth is promoted, and vice versa.

We found that $A$. confusa radicle elongation was inhibited under the stock solution and 1:20 litter extract; at 1:40, 1:80, and 1:160 litter extracts, we observed promotion effects, although it was not conspicuous at the concentration of 1:320 (Table 3). The stock solution had the strongest inhibiting effects on seed radicle growth. The best promotion effect was detected for the 1:160 litter extract which showed a relative high promotion effect in the early period, then later decreased. Consequently, the 1:160 litter extract remained the optimum concentration for the growth of $A$. confusa radicle length.

The results of the two-way ANOVA analysis of variance were presented in Table 4. There was a significant difference in the length of A. confusa radicle treated with time or different concentrations of litter extracts. But the difference in interaction between time and different treatments is not significant. 
Table 3. Allelopathic index of A. confusa radicle length in different concentrations of litter extracts

\begin{tabular}{c|c|c|c|c|c|c|c|c|c|c|c|c|c}
\hline Day & D3 & D4 & D5 & D6 & D7 & D8 & D9 & D10 & D11 & D12 & D13 & D14 & D15 \\
\hline $\begin{array}{c}\text { Distilled } \\
\text { water }\end{array}$ & 0 & 0 & 0 & 0 & 0 & 0 & 0 & 0 & 0 & 0 & 0 & 0 & 0 \\
$\begin{array}{c}\text { Control } \\
\text { group }\end{array}$ & -0.12 & -0.05 & -0.06 & 0.02 & -0.04 & 0.00 & 0.05 & 0.07 & 0.06 & 0.05 & 0.03 & -0.01 & 0.02 \\
$\begin{array}{c}\text { Stock } \\
\text { solution }\end{array}$ & -0.85 & -0.51 & -0.36 & -0.28 & -0.32 & -0.33 & -0.31 & -0.31 & -0.32 & -0.35 & -0.35 & -0.35 & -0.35 \\
$1: 20$ & -0.25 & -0.13 & -0.13 & -0.19 & -0.26 & -0.29 & -0.26 & -0.23 & -0.23 & -0.21 & -0.18 & -0.18 & -0.15 \\
$1: 40$ & 0.15 & 0.12 & 0.10 & 0.06 & 0.01 & 0.04 & 0.10 & 0.10 & 0.06 & 0.04 & 0.04 & 0.06 & 0.10 \\
$1: 80$ & 0.19 & 0.22 & 0.22 & 0.20 & 0.19 & 0.18 & 0.18 & 0.18 & 0.16 & 0.13 & 0.12 & 0.09 & 0.10 \\
$1: 160$ & 0.21 & 0.22 & 0.23 & 0.14 & 0.17 & 0.18 & 0.19 & 0.19 & 0.18 & 0.19 & 0.18 & 0.17 & 0.17 \\
$1: 320$ & -0.30 & -0.10 & 0.08 & 0.03 & -0.01 & 0.02 & 0.08 & 0.11 & 0.10 & 0.10 & 0.11 & 0.10 & 0.09 \\
\hline
\end{tabular}

Table 4. The two-way ANOVA analysis of two treatments on the radicle length of A. confusa

\begin{tabular}{c|c|c|c}
\hline & df & $\mathbf{F}$ & $\mathbf{p}$ \\
\hline Day & 12 & 274.867 & $<0.001^{* * *}$ \\
Leaching solution & 7 & 134.259 & $<0.001 * * *$ \\
Day : Leaching solution & 84 & 1.244 & 0.108 \\
Residuals & 208 & & \\
\hline
\end{tabular}

\section{Differences in radicle growth of A. confusa seeds in different time periods}

The effects of litter extracts on the seed radicle growth is shown in Figure 3. It shows that the seed radicle growth of $A$. confusa decreased with time, and the growth trends of various concentrations were different. The growth of the seed radicle was greater in the distilled water group at the period from day 4 to 9 , and the growth was stable after the 10th day. The radicle growth increased the most on the fifth day and the least on the 11th day. For the stock solution of litter extracts, the seed radicle growth during day 5 to 7 was significantly higher than on other days; the seed radicle grew the most on the fifth day and the least on the 13th day. The 1:20 litter extract group demonstrated the most seed radicle growth on the fifth day and the least on the eighth day; the seed radicle growth during the first eight days was relatively high compared to that on the following days. At the 1:40 concentration, the radicle growth was relatively high during day 4 to 10 (except for the eighth day); the maximum growth occurred on the fourth day, with the least growth on day 11 to 14, and the radicle growth gradually increased in the later stage. At 1:80 and 1:160 concentrations, the seed radicle growth showed a general downward trend, reaching the maximum on the fourth day, and stabilized after decreasing sharply on day 10 to 15 . The seed radicle growth at the 1:320 concentration reached a maximum on the sixth day, then declined from day 7 to 16 , and the least growth was observed on the 16th day. The different concentrations of litter extracts inhibited the seed radicle growth less in the early period, where the radicle growth was relatively fast, whereas the various concentrations of litter extract had different effects on seed radicle growth in the later stages. Compared with the distilled water group and the control group, the high litter extract concentrations inhibited the radicle growth of $A$. confusa, which was promoted at low concentrations. 
The $A$. confusa seed radicle growth was inhibited on day 7 to 9 and day 12 to 15 , and promoted on day 5 to 6 and 10 to 11 in general (Table 5). The inhibition effect was obvious in the stock solution and the 1:20 concentration litter extract. The promotion effect appeared in the 1:80, 1:160, and 1:320 litter extract concentrations. The different days and treatments, along with their interaction, significantly affected the radicle growth of A. confusa (Table 6). Overall, the 1:160 litter extract concentration was the optimum for the increase in $A$. confusa radicle length.

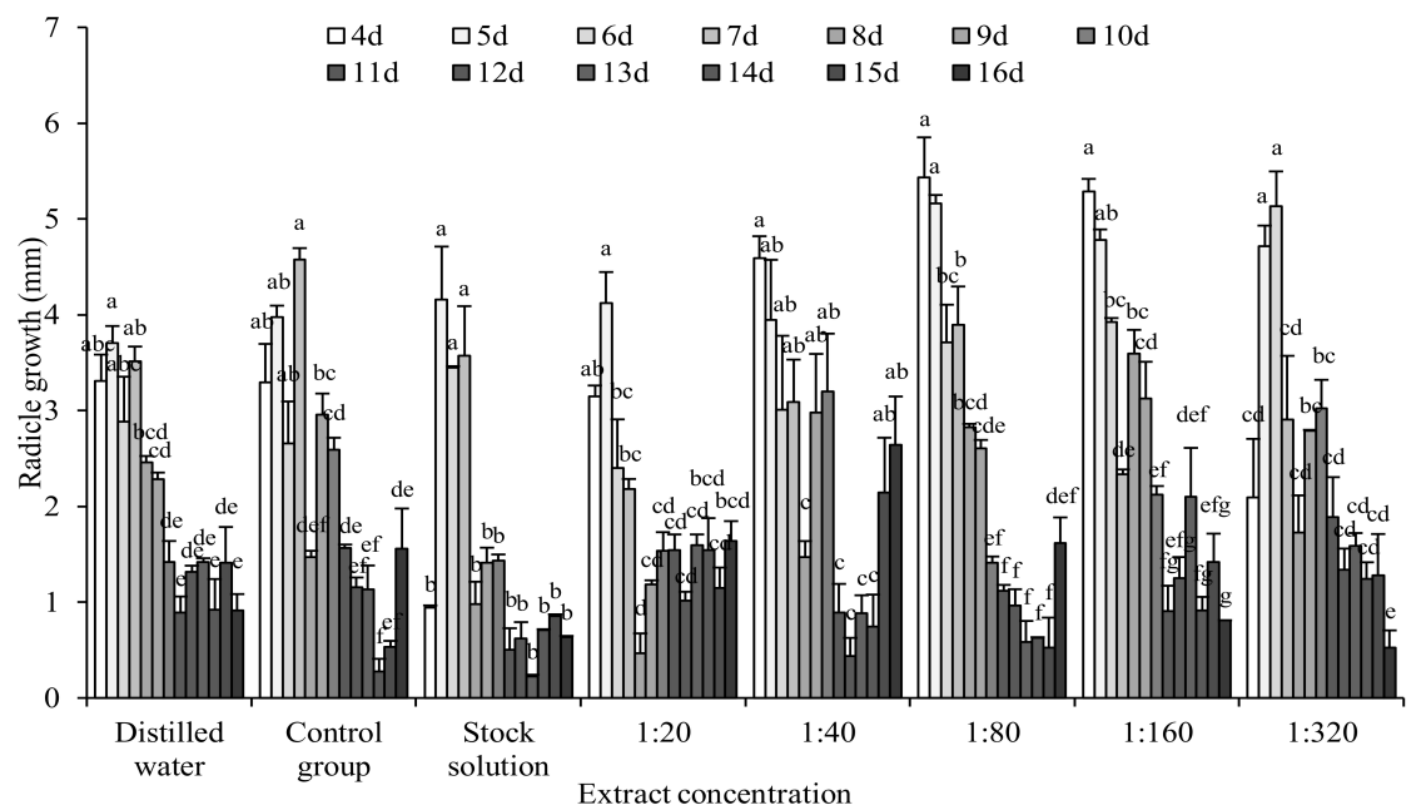

Figure 3. The seed radicle growth of A. confusa in different time periods. the different letters (from a to $g$ ) indicate the difference in radicle growth among different days under the same concentration.The amount of radicle growth refers to the length of the radicle from the next day minus the length of the radicle of the previous day. Data (mean $\pm S D$ ) marked with different letters in plots were significantly different under p level as 0.05 in the same column

Table 5. Allelopathic index of the seed radicle growth of A. confusa in different concentrations of litter extracts

\begin{tabular}{c|c|c|c|c|c|c|c|c|c|c|c|c|c}
\hline Day & D4 & D5 & D6 & D7 & D8 & D9 & D10 & D11 & D12 & D13 & D14 & D15 & D16 \\
\hline $\begin{array}{c}\text { Distilled } \\
\text { water }\end{array}$ & 0 & 0 & 0 & 0 & 0 & 0 & 0 & 0 & 0 & 0 & 0 & 0 & 0 \\
$\begin{array}{c}\text { Control } \\
\text { group }\end{array}$ & -0.01 & 0.07 & -0.08 & 0.23 & -0.40 & 0.23 & 0.45 & 0.43 & -0.12 & -0.20 & -0.70 & -0.62 & 0.41 \\
$\begin{array}{c}\text { Stock } \\
\text { solution }\end{array}$ & -0.72 & 0.11 & 0.16 & 0.02 & -0.60 & -0.38 & 0.01 & 0.44 & -0.53 & -0.84 & -0.23 & -0.39 & -0.31 \\
$1: 20$ & -0.05 & 0.10 & -0.17 & -0.38 & -0.81 & -0.48 & 0.08 & 0.42 & -0.23 & 0.11 & 0.40 & -0.19 & 0.44 \\
$1: 40$ & 0.28 & 0.06 & 0.04 & -0.12 & -0.40 & 0.23 & 0.56 & 0.00 & -0.67 & -0.38 & -0.19 & 0.34 & 0.65 \\
$1: 80$ & 0.39 & 0.28 & 0.22 & 0.10 & 0.13 & 0.12 & -0.01 & 0.20 & -0.27 & -0.59 & -0.32 & -0.63 & 0.44 \\
$1: 160$ & 0.37 & 0.23 & 0.26 & -0.34 & 0.32 & 0.27 & 0.33 & 0.01 & -0.05 & 0.33 & 0.00 & 0.01 & -0.11 \\
$1: 320$ & -0.37 & 0.22 & 0.44 & -0.17 & -0.30 & 0.18 & 0.53 & 0.53 & 0.02 & 0.11 & 0.26 & -0.09 & -0.43 \\
\hline
\end{tabular}

Day 4 represents the allelopathy index of the radicle growth amount obtained on the fourth day minus the third day, the same as Day 5 to Day 16. 
Table 6. The two-way ANOVA analysis of two treatments on the radicle growth of A. confusa

\begin{tabular}{c|c|c|c}
\hline & df & $\mathbf{F}$ & $\mathbf{p}$ \\
\hline Day & 12 & 94.677 & $<0.001^{* * *}$ \\
Leaching solution & 7 & 12.662 & $<0.001^{* * *}$ \\
Day: Leaching solution & 84 & 4.759 & $<0.001^{* * *}$ \\
Residuals & 208 & & \\
\hline
\end{tabular}

\section{Discussion}

With increasing litter extract concentration, the germination potential, germination rate, and germination index of $A$. confusa decreased. The stock solution and the 1:20 litter extracts concentrations had strongest inhibitory effect on seed germination. The germination potential and germination index of the seeds in the stock solution were the lowest, primarily due to the restraining effect of the allelochemicals in the stock solution on the speed of seed germination. The germination rate in the 1:20 litter extraction concentration group was the lowest and the negative effect of allelochemicals on the seeds were most pronounced. This may be caused by the amount of harmful ingredients in the allelochemicals, which were much more than the amount of beneficial components. Under normal circumstances, the production and elimination of free radicles in plant cells maintains a dynamic equilibrium; under stress conditions, this balance is affected and readily destroyed. When free radicals accumulate to a certain extent, membrane lipid peroxidation occurs, which inhibits seed germination (Shibaeva et al., 2018; Marusa and Ishii-Iwamoto., 2011). At the 1:160 concentration, the three seed germination indices were the highest, and the promotion effect was the most obvious. We speculate that this concentration is the optimum concentration of seed germination, and the beneficial components in the allelochemicals accumulate the most. Within this concentration range, the ion transporters in the cell and various ion channel proteins are involved in cell ion homeostasis, increasing seed germination rate and germination speed (Steven et al., 2003; Zhang et al., 2016; Bachleda et al., 2017; Kilic et al., 2016). The 1:320 litter extract concentration also promoted the germination of seeds, but the overall effect was not significant. The reason for this may be that the concentration was lower and similar to distilled water, and the allelochemicals content was relatively low; thus, the promoting effect was not obvious. In general, compared with the distilled water group, no germination index was significant for the lowconcentration litter extracts, whereas high-concentration litter extracts significantly inhibited the germination indices of $A$. confusa seeds. When the allelochemicals content is limited, the plant itself produces stress-resistant immunity. At this time, allelopathic chemicals have little effect on the plant. When the residual allelochemicals increase, accumulate, and increase to a certain amount or exceed the critical content, they are harmful to the plant and thus delay seed germination (Liu et al., 2016; Wei et al., 2018).

With the increase in litter extract concentration, the seed radicle growth of $A$. confusa showed an obvious hysteresis effect. The litter extracts had a significant inhibiting effect on seed radicle growth compared with distilled water, mainly because the seed radicle growth was inhibited by the stock solution and the 1:20 concentration. High litter extract concentrations may have physiologically disturbed the plant, inducing intensive anaerobic respiration, which would therefore weaken the plant's ability to scavenge free radicals, resulting in a decrease in its physiological index (Steven et al., 2003; Zhang et al., 2016; Bachleda et al., 2017; Kilic et al., 2016). The hormone content 
and enzyme activity in the seeds of $A$. confusa may have led to the inhibitory effect of litter extracts on seed germination and radicle growth within a certain concentration range (Hunter et al., 2013). When the litter extract concentration was 1:160, the promotion of radicle growth was the most obvious, and the content of beneficial allelochemicals was the highest. We speculate that the concentration of nutrients in this treatment was high, the breathing was strong, the high energy bond in ATP was active, the mitochondria inner membrane activity was strong, the rates of electron transfers and oxidative phosphorylation were fast, and the cell division speed of the apical meristem was accelerated, which effectively promote radicle elongation (Steven et al., 2003; Zhang et al., 2016; Bachleda et al., 2017; Kilic et al., 2016). The 1:320 litter extract also promoted the growth of seed radicle length, but the effect was weakened, which may be due to the litter extract dilution containing less effective allelochemicals. Previous studies have reported low allelopathic effect at low concentration and inhibition at high concentration with: water extracts from corn leaves on the seeds of Scutellaria baicalensis, litter extracts on seed germination and seedling growth of Cunninghamia lanceolate, and litter leaves and soil extracts on the seed germination and seedling growth of P. koraiensis (Chen et al., 2016; Peng et al., 2012; Zhuang et al., 2017). These results are consistent with our findings.

By analyzing the growth in the radicle over time, we discovered that the radicle growth of $A$. confusa treated with litter extract was relatively high in the early stage, and the growth the middle and late stages tended to decline. The reason for this may be that a certain amount of allelopathic substances accumulated in the litter, hindering the water absorption of the seed; inhibiting the respiration, enzyme activity, and radicle growth; and changing the osmotic pressure, thereby constraining the elongation of the radicle (Wei et al., 2018). When the litter extract concentrations were 1:40 and 1:80, the seed radicle growth of $A$. confusa increased gradually in the later stage, which may be due to the increase in peroxidation products in the plant after the stress due to allelopathic substances. When these allelopathic substances reach a certain amount and the stress mechanism is constrained by the plant, its own protective enzyme system could thereby scavenge the free radicals generated. However, this adaptive response is effective, as the degree of damage was relatively low and reversable, whereas the radicle increase was limited at any higher concentration of litter extract (Marusa and Ishii-Iwamoto, 2011).

The low litter extract concentration in nature can promote the germination and radicle growth of $A$. confusa to some extent. So, it is feasible to mix $A$. confusa in $C$. kawakamii forests. However, when mixing A. confusa, we should try to select a location where the amount of litter is low and the topography is relatively flat to mitigate the adverse effects of allelopathy. To afforest a successful mixed forest, further studies are required. Firstly, the effects of extracts from $C$. kawakamii natural forest on A. confusa should be studied from the perspective of the physiological activity of the radicle. Secondly, the different effects of various types and contents of litter allelochemicals at different forest ages and stages on seeds should be thoroughly considered during the afforestation of mixed forests (Hunter et al., 2013). Allelopathic effect on the plant are complex, having important impacts on the growth of plant seedlings (Kimura et al., 2015; Anne et al., 2019; Chu et al., 2014), thus affecting the colonization and renewal of the population. In the future, research should be continued on the growth response of C. kawakamii and A. confusa seedlings to litter extract. 


\section{Conclusions}

In this study, we examined the effects of different concentrations of $C$. kawakamii litter extract on the germination rate, germination potential, germination rate index, and radicle growth of A. confusa. Low concentrations promoted growth, whereas higher concentrations inhibited growth. The stock solution had the most obvious inhibiting effect on seed germination and radicle growth, whereas the 1:160 litter extract concentration displayed the strongest promotion. The natural leaching concentration of litter in the wild is about 1:160, which could actually promote the seed germination and radicle growth of $A$. confusa. Therefore, the allelopathic effect of forest litter is not a limiting factor when mixing $C$. kawakamii and A. confusa in a forest, providing an alternative method to improve soil nutrition in this forest, and finally promote the regeneration of $C$. kawakamii seedlings in this forest. Further study is needed of the physiological response of $A$. confusa radicle and growth to litter extracts to provide a practical basis to promote $C$. kawakamii regeneration in this forest.

Acknowledgements. The authors wish to thank Cong Xing, Chensi Wei, Xuelin Wang, Jing Zhu and Yaoshun Lu for assistance in the field and experiment. At the same time, the authors would like to thank Dr. Zhu Dehuang for the constructive comments and suggestions of the manuscript. This research was funded by the National Natural Science Foundation of China (NSFC), grant number 31700550 and 31770678; Nature Science Fund of Fujian Province Science and Technology of China, grant number 2019J01367; Science and Technology Promotion of Project Forestry Bureau of Fujian Province, grant number 2018TG14-2; and Innovation and Technology Fund of Fujian Agriculture and Forestry University, grant number CXZX2016075 and CXZX2018125. The authors also record sincere appreciation for helpful and constructive comments made by reviewers of the manuscript.

\section{REFERENCES}

[1] Aldo, B. F., Shovonlal, R., Vitor, M. V. (2018): Allelopathy prevents competitive exclusion and promotes phytoplankton biodiversity. - Oikos 127(1): 85-98.

[2] Anne, L., Leena, L. (2019): Responses of a native plant species from invaded and uninvaded areas to allelopathic effects of an invader. - Ecology and Evolution 9(10): 6116-6123.

[3] Bachleda, N., Timothy, L. G., Zeng, L. L. (2017): Effects of high oleic acid soybean on seed yield, protein and oil contents, and seed germination revealed by near-isogeneic lines. - Plant Breeding 136(4): 231-74.

[4] Bruce, W. G., Richardson, D. (1988): Bioassays for allelopathy: measuring treatment responses with independent controls. - Journal of Chemical Ecology 14(1): 181-187.

[5] Buanjan, S., Liu, J. F., He, Z. S., Feng, X. P. (2018): Effect of gap sizes on specific leaf area and chlorophyll contents at the Castanopsis kawakamii natural reserve forest, China. - Forests 9(682): 1-14.

[6] Chen, L. X., Li, S. B., Qiao, L., Bu, F., Duan, W. B. (2016): Effects of leaf litter and leaching liquor on seed germination and seedling growth of Pinus koraiensis. - Journal of Nanjing Forestry University 40(2): 81-87.

[7] Chu, C. J., Mortimer, P. E., Wang, H. C., Wang, Y. F., Liu, X. B., Yu, S. Y. (2014): Allelopathic effects of Eucalyptus on native and introduced tree species. - Forest Ecology and Management 32(3): 79-84.

[8] Feng, X. P., Liu, J. F., Buanjan, S. J., He, Z. S., Jiang, L., Hong, W., Shi, Y. W. (2017): Ecological stoichiometric characteristics of litter-soil in gap of Castanopsis kawakamii in Sanming of Fujian. - Journal of Plant Resources and Environment 26(4): 18-24. 
[9] Gabriel, M. M., Lourens, P., Pauline, B., Godefridus, M. M. (2017): Unleached prosopis litter inhibits germination but leached stimulates seedling growth of dry woodland species. - Journal of Arid Environments 138(1): 44-50.

[10] He, Z. S., Liu, J. F., Hong, W., Zheng, S. Q., Wu, C. Z., Wu, Z. Y., Lin, Y. J., Su, S. J. (2012): Effects of different treatments on seed germination of Castanopsis kawakamii. Journal of Beijing Forestry University 34(2): 66-70.

[11] He, Z. S., Liu, J. F., Zheng, S. Q., Hong, W., Wu, C. Z., Li, J. (2018): Diurnal variation of photosynthetic rates of Castanopsis kawakamii seedlings and their relationships with meteorological factors in forest gaps and non-gaps. - Pakistan Journal of Botany 50(4): 1361-1368.

[12] He, Z. S., Wang, L. J., Jiang, L., Wang, Z., Liu, J. F., Xu, D. W., Hong, W. (2019): Effect of microenvironment on species distribution patterns in the regeneration layer of forest gaps and non-gaps in a Subtropical Natural Forest, China. - Forests 10(2): 90-103.

[13] Hou, Y. P., Peng, S. L., Chen, B. M., Ni, G. Y. (2011): Inhibition of an invasive plant (Mikania micrantha H. B. K.) by soils of three different forests in lower subtropical China. - Biological Invasions 13(2): 381-391.

[14] Hu, F., Shi, Q., Huang, L. J. (2015): Induction of adventitious roots during tissue culture of Acacia mangium and A. auriculiformis elite trees. - Journal of Nanjing Forestry University (Natural Sciences Edition)39(2): 57-62.

[15] Hunter, M. E., Menges, E. S. (2013): Allelopathic effects of litter Axonopus compressus against two weedy species and its persistence in soil. - American Journal of Botany 23(1): 69-54.

[16] Kilic, K., Kara, Y., Vaizogullar, H. E. (2016): Allelopathic effects of Lyophyllum platypum mushroom extracts on seed germination of Cynanchum acutum subspecies acutum weed. - Journal of Biotechnology 231: S23.

[17] Kimura, F., Sato, M., Kato-Noguchi, H. (2015): Allelopathy of pine litter: delivery of allelopathic substances into forest floor. - Journal of Plant Biology 58(1): 61-67.

[18] Liu, G. X., Wan, L. Q., He, F. (2016): Effects of litter, seed position, and water availability on establishment of seedlings for two semiarid grass species. - Plant Ecology 217(3): 277-287.

[19] Liu, J. F., He, Z. S., Hong, W., Zheng, S. Q., Wang, Z. J. (2011): Conservation ecology of endangered plant Castanopsis kawakamii. - Journal of Beijing Forestry University 33(5): 136-143.

[20] Liu, X. L. (2011): Close to Nature Forest Management Model on Tropical Coast Casuarina equisetifolia Plantation. - Chinese Academy of Forestry, Beijing.

[21] Ma, R. F., Liu, J. F., Wu, Z. Y., Zhang, G. S., Chen, Z. F., Hong, W., He, Z. S. (2014): Soil microbial community structure diversity in Castanopsis kawakamii forest. - Journal of Southwest Forestry University 34: 14-19.

[22] Ma, R. F., Liu, J. F., Zhang, G. S., Wu, Z. Y., Hong, W., He, Z. S. (2015): Effects of forest gaps on soil properties in Castanopsis kawakamii nature forest. - Journal of Plant Resources and Environment 10(10): 19-27.

[23] Marusa, P., Ishii-Iwamoto, E. L. (2011): Changes in energy metabolism and antioxidant defense systems during seed germination of the weed species Ipomoea triloba L. and the responses to allelochemicals. - Journal of Chemical Ecology 37(5): 500-513.

[24] Peng, X. B., Zhang, S. X. (2012): Allelopathic effects of aqueous extract of maize leaf on Scutellaria baicalensis seeds. - Pratacultural Science 29(2): 255-262.

[25] Shibaeva, T. G., Sherudilo, E. G., Titov, A. F. (2018): Response of Cucumber (Cucumis sativus L.) response of Cucumber (Cucumis sativus L.) plants to prolonged permanent and short-term daily exposures to chilling temperature. - Russian Journal of Plant Physiology 65(2): 286-294.

[26] Steven, M. D., Malthus, T. J., Frédéric, B., Xu, H., Chopping, M. J. (2003): Intercalibration of vegetation indices from different sensor systems. - Remote Sensing of Environmen 88(4): 412-422. 
[27] Su, S. J., Liu, J. F., He, Z. S., Hong, W., Zhang, J. B. (2012): The spatial heterogeneity of soil nutrients in a mid-subtropical Castanopsis kawakamii natural forest. - Acta Ecologica Sinica 32(18): 5673-5682.

[28] Tung, Y. T., Chang, W. C., Chen, P. S., Chang, C. T., Chang, S. T. (2015): Ultrasoundassisted extraction of phenolic antioxidants from Acacia confusa flowers and buds. Journal of Separation Science 34(7): 844-851.

[29] Wang, G. Z., Peggy, S., Alice, T., Zhang, J. L., Zhang, F. S., James, D. B. (2019a): Soil microbiome mediates positive plant diversity-productivity relationships in late successional grassland species. - Ecology Letters. https://doi.org/10.1111/ele.13273.

[30] Wang, Z., Lan, Y. Q., He, Z. S., Liu, J. F., Xing, C., Zhu, J., Wang, X. L., Shi, Y. W., Shen, C. X. (2019b): Effects of Castanopsis kawakamii forest litter extract on its seed germination and radicle growth. - Journal of Fujian Agriculture and Forestry University (in press).

[31] Wei, Y. L., Mao, M. Q., Zhao, Y., Ma, M. D. (2018): Effects of aqueous extracts from Paris polyphylla seeds on seed germination and seedling growth of three kinds of plants. - Plant Science Journal 36(1): 94-102.

[32] Yang, S. Y., Lin, P., Gou, J. Y., Lin, R. Y., Chen, G. S., He, Z. M., Xie, J. S. (2003): Litter production, nutrient return and leaf-litter decomposition in natural and monoculture plantation forests of Castanopsis kawakamii in subtropical China. - Acta Ecologica Sinica 23(7): 1278-1289.

[33] Yuan, H., Hou, F. J. (2010): The allelopathy effect of litter from three dominant species on alfalfa seedlings growth in the Loess Plateau. - Pratacultural Science 27(06): 20-24.

[34] Zhang, F. Y., Du, Z. Z., He, J. W., Yang, L. Y. (2016): Effects of Eupatorium adenophorumii litter aqueous extract on its seed germination and seedling growth. Research of Soil and Water Conservation 23(3): 291-296+303.

[35] Zhuang, Z., Li, Y. J., Liu, Q. Q., Yang, Z., Liu, B., Liu, A. Q. (2017): Effects of Chinese fir litter extracts on the seed germination and seedling. - Journal of Forests and Environment 37(1): 29-33. 